\title{
A Sensitivity Analysis of Retailer Shelf Management Models
}

\author{
NORM BORIN \\ California Polytechnic State University \\ PAUL FARRIS \\ University of Virginia
}

\begin{abstract}
A shelf management model was developed to assist retailers with the decision of which products to stock and how much space to allocate to those products. Due to the non-linearities in the formulation a closed form solution is not possible. Borin, et al. develop a search heuristic based on simulated annealing and compare the solution against a known optimum. A barrier to the use of such models is the fact that managers typically do not have access to error-free estimates of the parameters required for the model construction (shelf elasticities, search loyalty, and consumer preferences). In this article we analyze the degree of error that may be introduced into estimates of the parameters before the model yields assortments and shelf allocations that are inferior to those produced by the merchandising rule of thumb. share-of-shelf = share-of-sales. The results indicate that judgmental estimates of parameters can vary by as much as 50 percent and still make application of the model useful.
\end{abstract}

\section{INTRODUCTION}

With limited shelf space and an abundance of current and new products, retailers must make decisions frequently ahout which products to stock and how much space to allocate to those products. Many retailers are now turning to shelf management models to help with these decisions. Within the last fifteen years there have been a number of models developed which incorporate some or all of these objectives (Anderson, 1979; Hansen and Heinsbroek, 1979; Corstjens and Doyle, 1981, 1983; Bultez and Naert, 1988; Bultez, Naert, Gijsbrechts and Vanden Abelle, 1989). However, these models suffer from two important problems, which often limit their effectiveness. First, because of non-linearities and complexities, the models must often be simplified before a solution set can be derived, which often reduces the usefulness of the models. Second, the number of parameters that must be estimated is large,

Norm Borin, California Polytechnic State University, School of Business, San Luis Obispo, CA 93407. Paul Farris, University of Virginia, Darden Graduate School of Business Administration, P.O. Box 6550, Charlottesville, VA 22906-6550. 
and estimation procedures introduce errors. When the effect of errors is unknown there is an understandable reluctance to employ mathematical models for assortment selection and space allocation.

This paper describes a shelf management model formulated by Borin, Farris and Freeland (1994) as a constrained optimization problem with two basic decision variables: product assortment and allocation of a fixed amount of space to the items in the assortment. The models' assortment and space allocation:

1. correspond to actual product dimensions and minimum pack-outs;

2. are based on differences in item profitability;

3. incorporate shelf-space elasticities and cross-elasticities among skus (stockkeeping units) in the same category;

4. consider the strength of consumer search loyalty to skus.

To find optimal or near-optimal assortment and shelf allocations a search heuristic based on simulated annealing may be used. However, since many inputs will be based on judgment they are subject to error in estimation and the usefulness of complex models and procedures can be questioned. Our focus is on the sensitivity of the model results to errors in the estimation of the parameters. The objective is to determine what the implications may be if a retailer sets a category shelf using incorrect parameter values. The results of this analysis show that the model is robust and can produce useful shelf space recommendations even when parameters are estimated with a large amount of error $(+/-50 \%)$.

We begin by examining the literature related to shelf management parameters and models. We then discuss the shelf management model and the search heuristic used to derive a solution set. Finally, we focus on the sensitivity analysis.

\section{LITERATURE REVIEW}

\section{Shelf Management Models and Studies of Shelf Space Elasticity}

If consumers were completely brand loyal and the product was always available, the space allocated to an item would have no effect on its sales (Anderson, 1979). Individuals would purchase the preferred item if it is present and either delay the purchase or go to another location if it is not available. However, past work (Carpenter and Lehmann, 1985; Ehrenberg 1965; Emmelhainz, Stock and Emmelhainz, 1991; Motes and Castleberry, 1985; Walter and Grabner, 1975) shows that many consumers are willing to compromise their initial choice and switch to another product, either because their brand was not available or the shelf display influenced their choice. In fact, there is evidence that many consumers' brand choice decisions are made at the point of purchase (Marketing News, 1982; Nielsen Marketing Research, 1992). For these consumers the brand choice may be influenced by one or more in-store merchandising factors-including space. 


\section{Shelf-Space Studies and Models}

Early studies in space management concentrated on establishing whether a relationship existed between an item's shelf space and its sales (Krueckeberg and Davis, 1966; Burgoyne and Johnston 1968; Cox, 1964, 1970; Frank and Massy, 1970; Kotzan and Evanson, 1969; Pauli and Hoecker, 1952). Even in view of the weak shelf space effects reported, much attention has been given to the construction of shelf models and the battle for retail shelf space between brands in the same category.

Typically, shelf-space models hypothesize that the ratio of sales/space decreases as space increases (Anderson, 1979; Brown and Tucker, 1961; Bultez and Naert, 1988; Bultez et al., 1989; Cairns 1962; Corstjens and Doyle, 1981,1983; Curhan, 1972, 1973; Hansen and Hcinsbrock, 1979). The non-lincarities in these models lead many of the authors to make simplifying assumptions in order to find a solution set.

\section{Assortment and Stockouts}

The literature available on consumer response to item stockouts indicates that in many cases shoppers resist compromising their original preferences (Peckham, 1963; Walter and Grabner, 1975; Walter and La Londe, 1975; Emmelhainz et al., 1991; Nielsen Marketing Research, 1992). These studies typically questioned individuals on their probable behavior if a desired item is missing, or removed items from the shelf, and used scanner data to measure the sales effects of these stockouts. Depending on the category, the percentage of consumers who would purchase elsewhere if their preferred brand was missing, ranged from 6 percent to 83 percent. Those numbers rose if the item was missing on a second occasion.

\section{Implications of Current Research in Space and Assortment Effects}

Current shelf management models focus on space responsiveness and neglect issues of assortment and stockouts (Anderson, 1979; Hansen and Heinsbroek, 1979; Corstjens and Doyle, 1981, 1983; Zufryden, 1986; Bultez and Naert, 1988; Bultez et al., 1989). The existing models allocate shelf space using only space elasticities, which have been shown to be weak. As Lee (1961) observed, using space elasticities to make assortment decisions invites problems that are compounded by the multiplicative model formulation used in many models.

The possibility that consumers may be unwilling to switch to other items if their item is permanently or temporarily missing implies that the assortment variable is a critical part of shelf management. In addition, the simultaneity of assortment and shelf space decisions due to category space constraints demands that space and assortment be modeled as an interactive relationship. The shelf management model developed here accomplishes this goal and produces a logically consistent model that can be optimized effectively.

\section{SHELF MANAGEMENT MODEL}

The shelf management model reflects four different sources of sales for a given SKU. 


\section{Unmodified Demand}

Unmodified demand represents the intrinsic preference for the SKU and is usually estimated using laboratory experiments conducted to gather brand or SKU choice when consumers are asked to select from a group of SKUs that receive the same merchandising treatment, i.e., demand for SKUs is unmodified by in-store support. Unmodified demand is similar to Farris, Olver and De Kluyver's (1989) unmodified preference which represented a brand's market strength exclusive of in-store support, Shugan's alpha (1989) which measured a brand's absolute market potential, and Corstjens and Doyle's alpha $(1981,1983)$ which measured the effects of all marketing variables except space. Unmodified demand will be measured by Farris et al.'s (1989) unmodified preference which represents a brand's market strength exclusive of in-store support.

\section{Modified Demand}

The concept of modified demand reflects the differential in-store merchandising support each SKU receives. The in-store support an SKU may receive includes space, shelf location, special displays, shelf tags, backroom inventory and window displays. A brand may also receive special support if the retailer stocks a relatively large number of its sizes or varieties. In our model we assume that differences in in-store merchandising support are solely a function of space allocation and other variables are held constant, therefore they are reflected in $P_{i}$. The "unmodified" demand of each SKU is "modified" to reflect its differential space allocation. Much of the reviewed literature supports decreasing marginal sales response to an SKU's own space. In addition, space models typically incorporate the negative effects of space allocated to other SKUs. If some SKUs are more directly competitive than others, i.e., have higher cross-elasticities, sales of an item can be affected by reallocation of space among competitive brands. The most parsimonious model that allows for: (1) competitive interactions; (2) decreasing returns; and (3) relative ease of estimation is the multiplicative model. Multiplicative models are well represented in the marketing literature including pricing (Reibstein and Gatignon, 1984); marketing mix decisions (Urban, 1969); space models (Bultez and Naert, 1988; Bultez et al., 1989; Corstjens and Doyle, 1981, 1983).

Equation 1 presents the model for modified demand which incorporates both direct and cross-space elasticities. The total number of parameters in the modified demand model is $n$ $\times n+n$ where $n$ is the number of SKUs in the category.

$$
\text { Modified Demand }{ }_{\mathrm{i}}=\mathrm{M}_{\mathrm{i}}=\mathrm{P}_{\mathrm{i}} \beta_{\mathrm{i}}
$$

where:

$$
\begin{aligned}
\beta_{i} & =\text { in-store attractiveness } \\
& =\prod_{j=1}^{n} s_{j}^{y_{i j}} \\
P_{i} & =\text { unmodified demand for sku } i
\end{aligned}
$$




$$
\begin{aligned}
z_{i} & =\text { space allocation for SKU } i \text { (number of facings) } \\
s_{j} & =1 \text { if } z_{j}=0 \\
& =z_{j} \text { if } z_{j}>0 \\
s_{i} & =0 \text { if } z_{i}=0
\end{aligned}
$$

\section{Acquired Demand}

Acquired demand is the portion of the shelf management model that captures the effects of assortment decisions. To formulate acquired demand, assume there exists a market with $n$ SKUs, $n_{1}$ of which are part of the category assortment, and $n-n_{1}$ of which have been excluded from the retailer's shelf. Each of the $n_{1}$ SKUs stocked captures a portion of the available sales that each of the $n-n_{1}$ SKUs would have obtained, if they had been stocked. The available sales from each missing SKU will be determined by its potential modified demand and the consumers willingness to switch to the $n_{1}$ available SKUs.

$\mathrm{SKU}_{\mathrm{i}}$ 's acquired demand will consist of two parts in a multiplicative relationship:

1. $S K U_{i}$ 's relative sales strength. Prior research (Emmelhainz et al., 1991) indicates that large market share SKUs receive a greater portion of the sales from those SKUs which are absent. To ensure that all of the $n-n_{1}$ item's available sales are distributed amongst the remaining $n_{1}$ items an attraction model is:

$$
\frac{\gamma_{i j} \mathrm{P}_{\mathrm{i}} \beta_{\mathrm{i}}}{\sum_{\mathrm{i}=1}^{n_{1}} \gamma_{\mathrm{ij}} \mathrm{P}_{\mathrm{i}} \beta_{\mathrm{i}}}
$$

The numerator represents the modified demand for $\mathrm{SKU}_{\mathrm{i}}$ while the denominator sums the modified demand of all of the stocked SKUs. This fraction will sum to one across all stocked SKUs. The degree of substitutability with the missing SKUs will also affect the level of acquired demand. The higher the cross-elasticity value the stronger the effects of a change in the space allocation of $\mathrm{SKU}_{\mathrm{j}}$ will have on the sales of another SKU. Combining the information available in the cross-elasticities with the relative SKU strength produces $\mathrm{SKU}_{\mathrm{i}}$ 's share of the available sales from the non-stocked $S_{\mathrm{j}}$. Note that it is the relative sizes of the $\gamma$ terms that, together with $\mathrm{P}_{\mathrm{i}}$ and $\mathrm{B}_{\mathrm{i}}$, determine the proportion of acquired demand obtained from $j$.

2. The amount of sales potentially available from $j$ will depend upon its modified demand. However, some of $\mathrm{SKU}_{\mathrm{j}}$ 's sales will be lost to the store because some fraction of buyers, represented by $\alpha_{i}$, will be resistant to compromising their original purchase choice. Therefore, $1-\alpha_{j}$ represents the fraction of $j$ 's sales that will be distributed amongst the $n_{1}$ stocked items. Equation 3 presents the demand from $\mathrm{SKU}_{\mathrm{j}}\left(\mathrm{SKU}_{\mathrm{j}}\right.$ was dropped from the assortment) that is available to be distributed to the stocked SKUs.

$$
P_{j} \beta_{j}\left[1-\alpha_{j}\right]
$$


Incorporating these factors into the model produces $\mathrm{SKU}_{\mathrm{i}}$ 's acquired demand presented in Equation 4. To summarize, Part 1 of the equation represents $\mathrm{SKU}_{\mathrm{i}}$ 's proportion of the available demand from non-stocked SKUs. Part 2 presents the demand from the non-stocked SKUs.

Part 1 Part 2

where:

$$
A_{i}=\sum_{j=n_{1}+1}^{n}\left[\frac{\gamma_{i j} P_{i} \beta_{i}}{\sum_{i=1} \gamma_{i j} P_{i} \beta_{i}} \quad P_{j} \beta_{j}\left[1-\alpha_{j}\right]\right]
$$

\section{Stockout Demand}

Finally, the complete model must include a correction for the possibility that the predicted sales from unmodified, modified and acquired sources exceeds the shelf inventory for a given SKU. If the sum of the unmodified, modified, and acquired demand for an item is larger than the item's inventory (a stockout), then this difference is potentially available to the SKUs that are in stock. By applying the loyalty factors (alpha), we can determine exactly how much of a stockout is available for the other SKUs. ${ }^{1}$ This amount is then allocated to other items that are in stock in the samc proportion as used in Equation $\mathbf{4}$ for acquired demand. The amount allocated to an item is a stockout gain.

This procedure is iterative because when the allocation is made to other items, it may cause the inventory to be exceeded for these items. If so, a new stockout loss is calculated, and ( 1 - alpha) of this amount is allocated to those remaining SKUs that are not stocked out. This process continues until either all items have stocked out or the sum of the unmodified, modified, and acquired demand and the total stockout gain does not exceed the inventory.

We use the same loyalty factors for both temporary out-of-stock situations and permanent adjustments to product assortment. In practice, one might argue that a temporary out-of-stock would be associated with different loyalties than one which the consumer recognizes as part of a store's assortment. We know of no published empirical studies which address this issue.

\section{SOLVING THE SHELF MANAGEMENT MODEL}

The shelf management model is expressed as a constrained optimization problem. The decision variable, $z_{i}$, represents the number of facings allocated to $S K U_{i}$. The objective function represents the category's return on the retailer's cost of total shelf inventory. The space constraint states that the sum of the space allocated to the SKUs must be equal to the 
stipulated category space level. Space constraints also place lower and upper limits on an individual SKU's space and establish the desired relationship between the space variables and the zero-one indicator variables.

\section{Shelf Management Problem}

Find Space $_{\mathrm{i}} \forall_{1}$ in order to:

$$
\begin{aligned}
& \sum^{n} G_{i} \operatorname{Price}_{i}\left(M_{i}+A_{i}+B_{i}+L_{i}\right) \\
& \text { Maximize } \Pi=\frac{i=1}{n} \\
& \sum_{\mathrm{i}=1}\left(1-\mathrm{G}_{\mathrm{i}}\right) \text { Price }_{\mathrm{i}} \text { Inventory } \mathrm{i}_{\mathrm{i}}
\end{aligned}
$$

subject to:

$$
\begin{aligned}
\sum_{\mathrm{i}=1}^{\mathrm{n}} \text { Space }_{\mathrm{i}} & =\text { Total Category Space } \\
\text { Space }_{\mathrm{i}} & \leq \text { Total Category Space } \\
\text { Space }_{\mathrm{i}} & \geq \text { Casepack }_{\mathrm{i}} \\
& =\text { if item } i \text { is stocked }
\end{aligned}
$$

where:

$$
\begin{aligned}
\mathrm{II} & =\text { Category Return on Inventory } \\
n & =\text { number of SKUs in category } \\
\mathrm{G}_{\mathrm{i}} & =\text { Gross Margin of } \mathrm{SKU}_{\mathrm{i}} \\
\mathrm{M}_{\mathrm{i}} & =\text { Modified Demand of } \mathrm{SKU}_{\mathrm{i}} \\
\mathrm{A}_{\mathrm{i}} & =\text { Acquired Demand of } \mathrm{SKU}_{\mathrm{i}} \\
\mathrm{B}_{\mathrm{i}} & =\text { Stockout Benefit of } \mathrm{SKU}_{\mathrm{i}} \\
\mathrm{L}_{\mathrm{i}} & =\text { Stockout Loss of } \mathrm{SKU}_{\mathrm{i}} \\
\text { Inventory } & =\text { Units of } i \text { on hand at beginning of period }
\end{aligned}
$$

Given the non-linearities and zero-one decision variables, it is not possible to get a closed form solution. However, the nature of the problem seems suited for simulated annealing (SA) because: (1) for the typical number of items in a category, the number of possible combinations is too large for complete enumeration; (2) functions are highly non-linear; and (3) simulated annealing provides a number of alternative solutions that can be evaluated on criteria not included in the model.

\section{Simulated Annealing ${ }^{2}$}

Simulated annealing is a combinatorial optimization algorithm, which finds near-optimal solutions for different kinds of problems. Our objective for the shelf management problem 


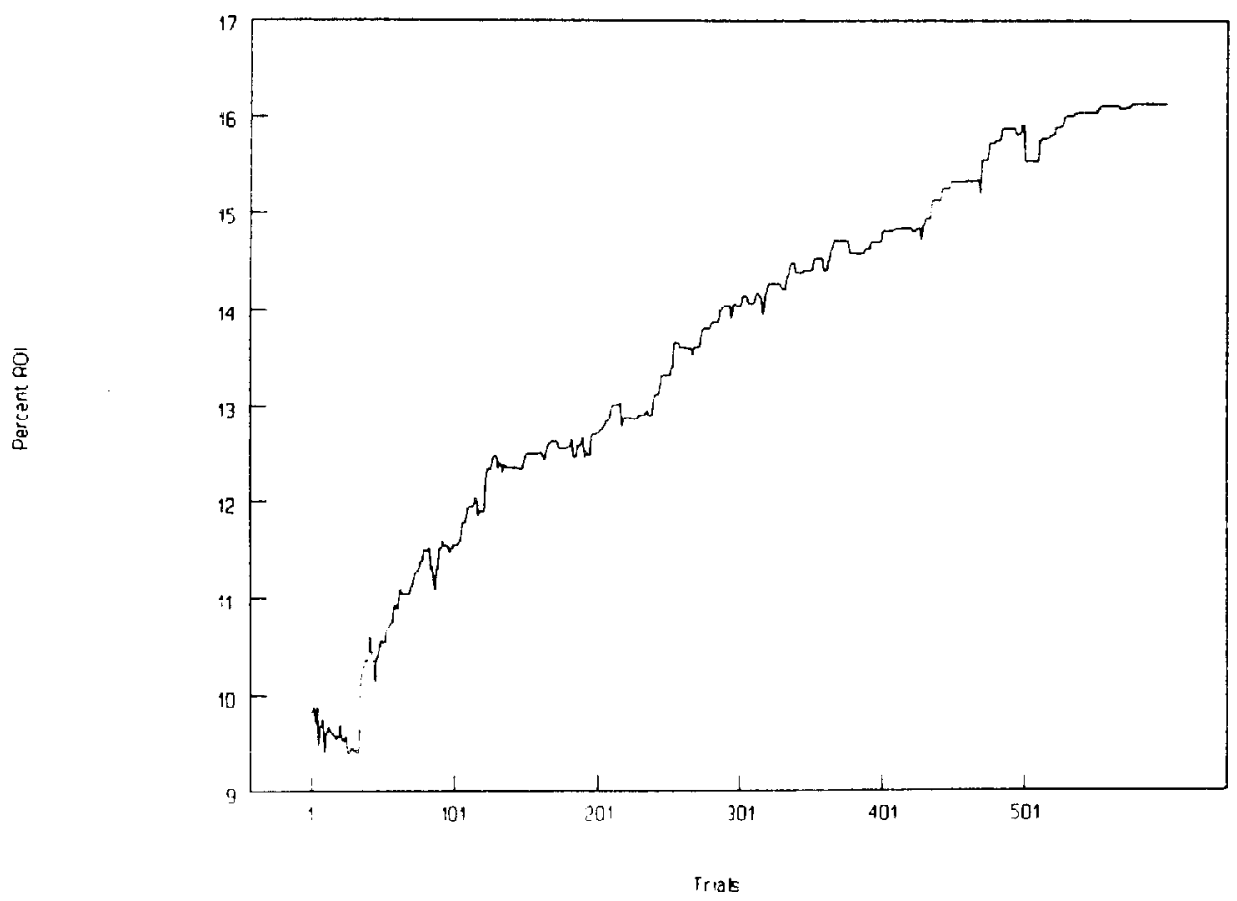

Figure 1. Example of Simulated Annealing Search Process

Item

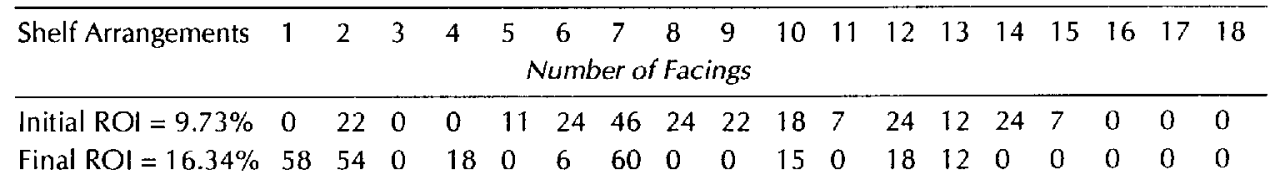

is to find an optimal allocation of space and assortment of SKUs so as to maximize the return on inventory. When applying simulated annealing to this optimization problem, we need to change (or randomly mutate) the set of SKUs in the assortment and the space allocated to each, and then accept those scts that improve the objective function value. However, if we do not allow for the acceptance of a few poor solutions, which may lead us to even better solutions, we may get stuck at a local maximum (like the top of a small hill, rather than the peak in a mountain range). Simulated annealing allows for this kind of a decision process. Simulated annealing will also produce a range of solutions which might be quite different shelf-arrangements or even assortments, but which are relatively close in terms of performance. Thus it may be more managerially useful than analytical solutions which guarantee optimality, but which may not illuminate other, near-optimal solutions.

In order to test the performance of SA on the shelf management problem, data from a ketchup category were collected from a local supermarket. The shelf management model 
parameters were derived based on past research experience. The shelf management model parameters can be estimated in one of three ways: (1) in-store experiments using warehouse data, scanner data, personal interviews together with shelf manipulations such as deliberate stockouts and space changes; (2) using past results reported in the literature; and (3) managerial judgment of parameter values. For the purposes of testing the technical characteristics of the model, the parameter values derived from past research and management judgment were assumed to be the "true" values. The simulated annealing heuristic was used to search for a good shelf configuration with the shelf management model. The search procedure begins at a randomly selected starting allocation (a feasible allocation of space to the SKUs). A new shelf allocation is selected within the "neighborhood" of the original one. Consistent with retailer practice, each neighborhood move will represent an exchange between items on the shelf. This may represent simply an exchange of a facing of one item for another, or if the items are different sizes (package widths), multiple items may be involved in one neighborhood exchange. As this process continues new items are continually added or deleted from the assortment.

The return on inventory of this new allocation is compared against the sales from the previously accepted shelf set, and if it is larger, the new allocation is automatically accepted. However, if it is smaller, there is a probability with which it may still be accepted.

Figure 1 illustrates the search pattern for the heuristic as well as the ROI and shelf arrangements for the randomly selected first shelf and the maximizing shelf arrangement. The figure demonstrates that a stable shelf arrangement has been reached. This process was repeated 25 times to determine the best category shelf arrangement. The maximum return on inventory found was 16.34 percent.

\section{SENSITIVITY OF MODEL RESULTS TO PARAMETER ERRORS}

This section examines model sensitivity to possible parameter estimation errors. Bultez and Naert (1988) also investigated the sensitivity of the shelf allocation model to errors in parameter estimation and found that the sensitivity of the model's performance to errors in parameter estimation was quite small. These authors observed that "this low sensitivity is partly due to the fact that the measurement error is assumed to have the same size and direction for all items. .." (Bultez and Naert used the same value for shelf elasticity for all brands). The present study will extend their work in four ways: (1) we use different elasticities for different SKUs; (2) the errors are not assumed to be equal in either size or direction; (3) we use assortment as well as space elasticities; and (4) a different optimization technique is employed. The specific procedure is described below:

1. Assume a set of true parameter values, $\mathrm{P}$ (see Borin et al. for the specific values).

2. Calculate the maximum return on inventory, ROI.

3. Select a new set of parameters, $P_{1}$, with a known standard deviation around the true set. Although each individual parameter will differ from its true level, the net change (expected) over all parameters will be zero.

4. Calculate the maximizing shel[ arrangement, $\mathrm{SA}_{1}$, derived with the incorrect parameters, $P_{1}$. 
5. Using $\mathrm{SA}_{1}$ calculate the category return on inventory, $\mathrm{ROI}_{1}$, predicted from the shelf management model with the true parameters, $\mathrm{P}$.

6. Calculate the decreased return $\left(\mathrm{ROI}-\mathrm{ROI}_{1}\right)$ that was created from setting the shelf using the incorrect parameter values, $\mathrm{P}_{1}$.

\section{Selecting the New Parameters}

A different array of parameters will be selected to represent various errors in manager estimation. Each set of parameters will lead to a different shelf allocation which, by definition, should result in a return on inventory below 16.34 percent when the shelf management model is applied using the true parameter values and the alternative shelf allocation.

The first step in selecting a set of incorrect parameters was to randomly sample a uniform distribution. These values were then transformed into a standard normal distribution using a scheme developed by Box and Muller (as described by Hogg and Craig, 1978). If $U_{1}$ and $\mathrm{U}_{2}$ represent samples from a uniform distribution over $0<u<1$ then:

$$
\begin{aligned}
& X_{1}=\left(-2 \ln U_{1}\right)^{1 / 2} \operatorname{Cos}\left(2 \pi U_{2}\right) \\
& X_{2}=\left(-2 \ln U_{1}\right)^{1 / 2} \operatorname{Sin}\left(2 \pi U_{2}\right)
\end{aligned}
$$

are independent normal deviates.

In sampling from these standard normal distributions, a series of normal distributions were then produced with each distribution representing a range of possible parameter errors with a known probability distribution. For example, a distribution was created with 99 percent confidence that the sampled values would lie between -.30 and $.30 .^{3}$ This distribution represented a set of parameters which varied from -30 to +30 percent of the true value with a mean difference of zero. If this distribution was sampled 100 times a mean absolute value could be calculated that would represent the average absolute percentage error from the true value. A number of such distributions was produced from a low of $+/-10$ percent from the true value to a high of $+/-150$ percent.

\section{Calculating the Error in Category ROI}

Each shelf management parameter was transformed using a value sampled from one of the normal distributions. Although each distribution had a mean of zero, the net change across all parameters was not exactly zero due to the desire to maintain logical consistency for selected parameters. These logical consistencies included:

1. The unmodified preferences, $P_{i}$, across the items must add to one. Therefore, each of the $P_{i}$ 's measured with error was divided by the sum of all $P_{i}$ 's. Each $P_{i}$ is constrained to be between zero and one.

2. All cross elasticities were constrained to be in the range of $-1,0$.

3. All own elasticities were constrained to be positive and less than one. 
4. All $\alpha$ 's were constrained to fall between zero and one.

For consistencies 2-4, if the variable exceeded the designated range, it was set to the upper or lower value. For example, if the adjusted $\alpha$ exceeded one, its value was set to one.

The simulated annealing algorithm was used to calculate the optimal shelf arrangement for the incorrect parameters. This arrangement was then used to calculate the return on inventory predicted from the shelf management model using the true parameters. The absolute and percentage error was then computed using the results for the ketchup category (maximum category return on inventory $=16.34$ percent). This process was repeated 100 times for each of the normal distributions.

The above procedure was repeated for three sets of true parameters. The first two sets were selected according to the process outlined in Borin et al. The third set of parameters were also selected according to this process but without the constraints listed above. ${ }^{4}$

\section{Sensitivity Results from Errors in Parameter Estimation}

Figure 2 illustrates, the percent deviation in error from the optimal. Table 1 presents the mean value for each distribution for all three sets of parameters.

\section{TABLE 1}

\begin{tabular}{cccc}
\multicolumn{4}{c}{ Reduction in Category Sales from Using Incorrect Parameter Values } \\
\hline $\begin{array}{c}\text { Mean Absolute Percent } \\
\text { Error in Parameter } \\
\text { Estimation }\end{array}$ & \multicolumn{3}{c}{ Mean Percent Deviation from Optimal* } \\
\cline { 2 - 4 } & Parameter Set 1 & Parameter Set 2 & Parameter Set 3 \\
\hline $3.09 \%$ & $1.55^{* *}$ & 1.27 & 3.97 \\
$6.19 \%$ & 1.68 & 2.04 & 4.10 \\
$9.27 \%$ & 2.17 & 2.45 & 4.37 \\
$12.37 \%$ & 2.65 & 3.48 & 4.22 \\
$15.45 \%$ & 3.24 & 3.00 & 5.12 \\
$18.55 \%$ & 3.86 & 4.86 & 5.22 \\
$21.66 \%$ & 4.57 & 5.68 & 5.51 \\
$24.75 \%$ & 5.53 & 6.88 & 5.05 \\
$27.84 \%$ & 6.48 & 7.83 & 6.22 \\
$30.91 \%$ & 7.36 & 8.82 & 6.57 \\
$34.00 \%$ & 7.98 & 9.76 & 7.50 \\
$37.10 \%$ & 9.23 & 11.13 & 7.98 \\
$40.22 \%$ & 10.03 & 12.89 & 8.51 \\
$43.29 \%$ & 11.22 & 14.0 & 9.43 \\
$46.38 \%$ & 11.83 & 14.8 & 10.25 \\
\hline
\end{tabular}

Notes: *Maximum ROI values for the three sets of parameter were $16.34 \%, 19.48 \%$, and $22.39 \%$ for sets 1,2 , and 3 respectively.

${ }^{* *} 1.55 \%$ change in $\mathrm{ROI}$ represents a .25 percent point change in the base $\mathrm{ROI}$ of $16.34 \%$. 


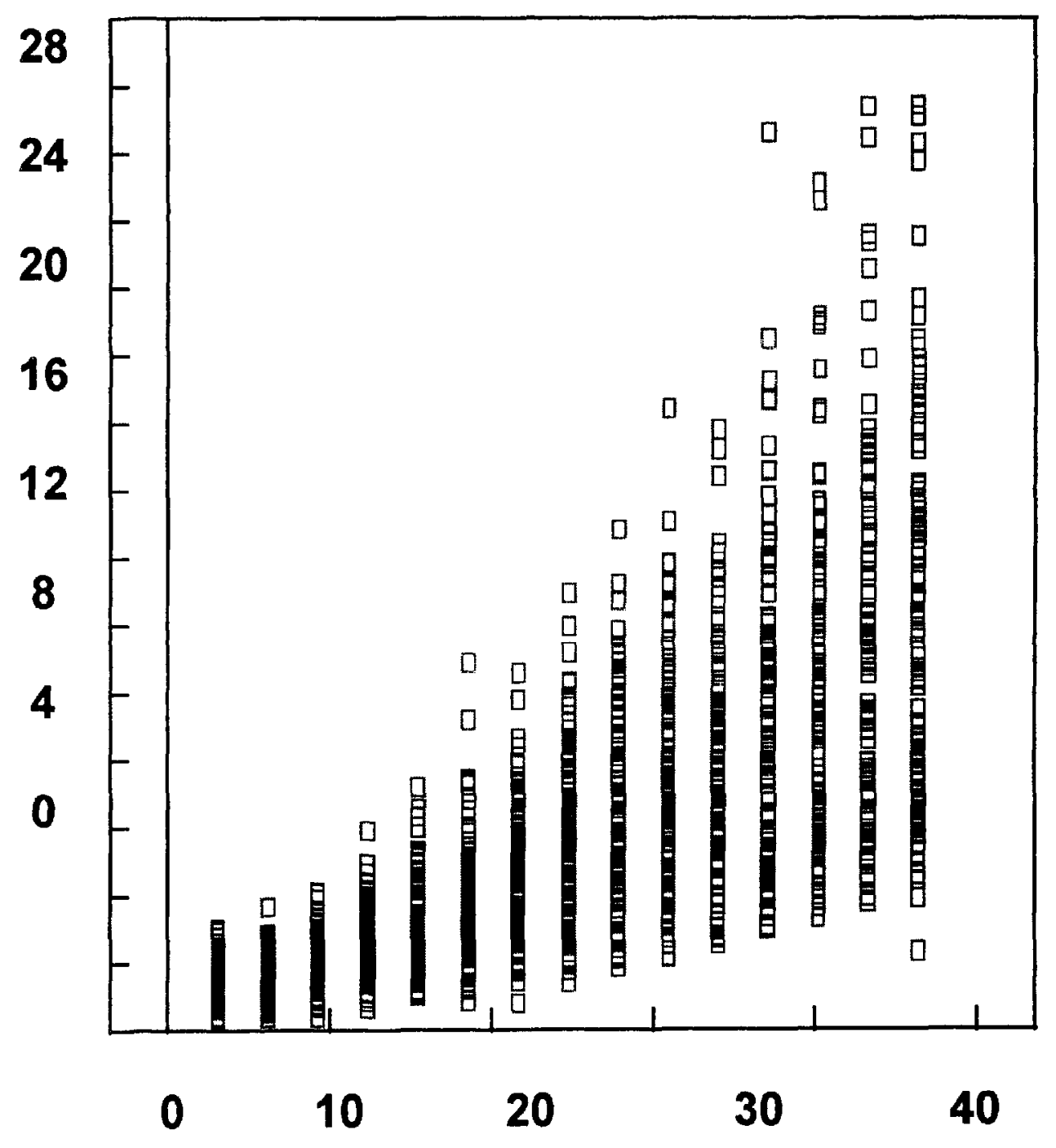

\section{Mean Absolute Percent Error (\%)}

Figure 2. The Effects of Parameter Error on ROI. Vertical Axis: (Model Max - Model-with-error)/Model Max

The results from the analysis reveal a number of insights. First, both the variance and mean value of the deviation rises as the mean absolute value in parameter error increases. Second, the mean absolute value in parameter error can be relatively large and the category return on inventory loss still be within five percent of the optimal value. These results indicate that parameters based on managerial judgments that contain sizable errors may still be useful for 


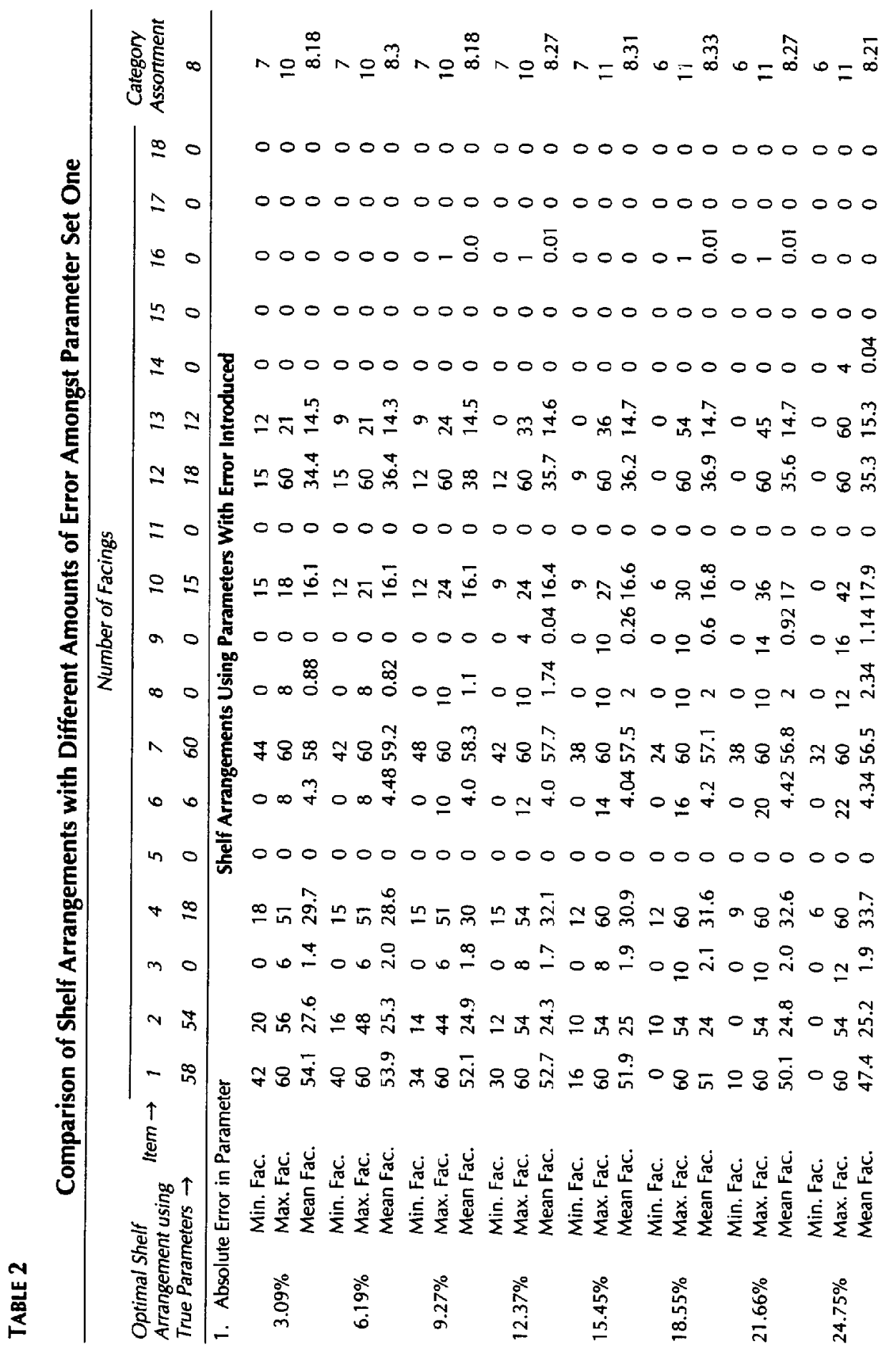




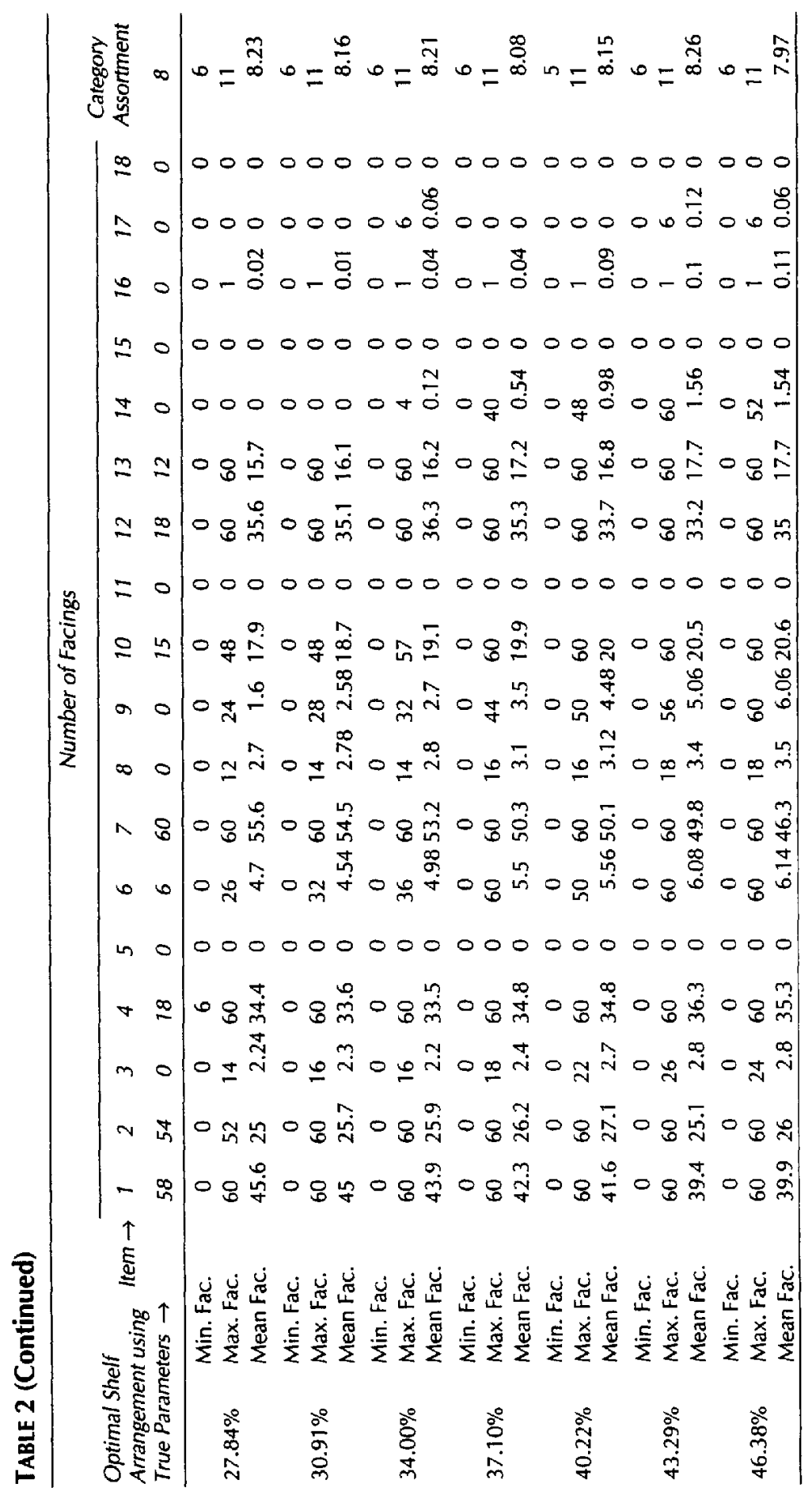


applying the shelf management model to derive the optimal space and assortment within a category.

Table 2 presents the maximizing shelf arrangements found for both the true parameter set and the summary results for the parameter error sets. The minimum and maximum facings for each item is presented for the maximizing shelf arrangement found for each of the 100 runs done at each distribution level. The last column in the table shows number of items selected for the assortment. For most of the error distributions, the mean values of both facings and assortment were relatively close to the optimal. Interestingly, as the error in parameter estimation increases all items are dropped from the assortment at one time or another.

\section{MODEL-GENERATED RESULTS VERSUS AN ALTERNATIVE HEURISTIC ${ }^{5}$}

\section{Alternative Heuristic}

A key question for managers is how the shelf management model performs relative to other procedures that grocers use to allocate space. Other shelf allocation programs exist and are employed by some retailers. It is not possible for us to perform a similar analysis with these programs, because their algorithms are proprietary. However, we can compare our results with those that would have been obtained from a commonly used "rule-of-thumb" that retailers use to determine shelf allocation. This rule allocates spaces to individual items in a manner that equates (approximately) the item's share of shelf to its share of market. Because of limited shelf space, the practice of having minimum "packouts" will typically cause some slow-selling products to have a share of shelf that is greater than their share of market. Indeed, a frequent complaint of large-share brands is that their share of shelf is less than their share of market. There are other problems with the implementation of such a "share-of-shelf = share-of-market" rule. One of the main problems is that changing shelf allocation changes market share, which changes the target shelf share, and there is no guarantee that a stable solution will be found. In practice, however, many retailers are able to use this procedure to allocate space (Ireland, 1993). They simply don't worry too much about marginal items and can just eliminate them from the assortment. These according to a survey of grocery buyers by slow-moving items are the ones that are usually (Farris et al., 1989) subject to being eliminated to make room for the new products in the category.

Applying the share-of-shelf $=$ share-of-market rule requires that an initial assortment be selected, and as we have argued, assortment selection is a problem with most space allocation procedures that do not explicitly consider search loyalty. Starting with equal shelf allocations (identical assortment), the model generated a new set of sales numbers, and the process was continued until a stable solution was found. The results are presented in Table 3.

A second application of the same procedure started with the entire assortment (all 18 items) and resulted in a shelf allocation with an ROI that was again less than the best shelf allocation found with the model. Our question is: How bad could the parameter estimates of managers be and still beat the share-of-shelf=share-of-market rule? We found that managers could be 
Comparison of SA and Share of Shelf $=$ Share of Sales Heuristics

\begin{tabular}{lcc}
\hline Heuristic & ROI (\%)Percentage & $\begin{array}{c}\text { Decrease in ROI from } \\
\text { Maximum }\end{array}$ \\
\hline Simulated Annealing & 16.34 & $\mathrm{NA}$ \\
Share of Shelf $=$ Share of Sales (Identical Assortment) & 12.60 & 22.9 \\
Share of Shelf $=$ Share of Sales (Total Assortment) & 11.21 & 31.4 \\
\hline
\end{tabular}

in error with their "guesses" of the parameters used in the model by as much as 50 percent and still outperform the share-of-shelf=share-of-market rule of thumb.

\section{DISCUSSION}

The number of parameters required for the shelf management model is $2 n+n^{2}$ where $n$ is the number of items in the category. Thus, even for a moderately sized category the number of required parameters becomes quite large very quickly. There are three alternatives to obtaining these parameters: (1) experimental design and estimation; (2) parameters gathered from the existing literature; and (3) managerial estimates of the values. The difficulties with calculating some of the required parameters using in-store experiments include time, money, and the large number of influencing factors that are extremely difficult to control in a supermarket. These influencing factors can lead to errors in the estimation of the parameter values. Data from existing literature is often incomplete and inadequate to the task of deriving parameter values. Managerial input can be very subjective. An additional complication is that market situations change quickly, and parameter estimates may need to be updated continually. Finally, without knowing how "rough" the optimal solution surface is, the usefulness of the model might remain in doubt, and managers would have little incentive to employ it.

This research has investigated the possible effects of setting a category shelf allocation using incorrect parameter estimates which may have been gathered from any of the three methods mentioned. The results indicate that, although the loss in category ROI, as well as the final shelf arrangement, rises with the error in parameter estimation, the mean absolute error in parameter values can be over 24 percent with a net loss in maximum category return on inventory of just over 5 percent. At the same time, the model significantly outperformed shelf allocations that were derived from the share-of-shelf $=$ share-of-market rule These results should increase managerial confidence in the ability of mathematical models to help rationalize assortment and shelf planning. Further research might explore the effects each of the shelf model parameters has on the final shelf arrangement. Certain parameters may be the key drivers behind the space and assortment decisions. The results from this analysis could help to simplify the model. Another aspect of research that might be worth exploring is whether simulated annealing "tries" shelf arrangements and assortments that managers 
would be unlikely to try in practice. Other research has shown that managers tend to be overconfident in some aspects of their decision making because they underestimate the range of possible outcomes. In other words, some possibilities are not even considered.

Although retailers have explored the interrelationships amongst their categories for sometime, there has been a paucity of models in this area. We believe that our model could be adapted to determine the assortment and space amongst a number of categories. Crosscategory space and assortment effects would be an interesting extension of this project and could assist retailers in determining whether their category space is optimal. Finally, we have modeled a view of the problem that starts with assumption about SKU loyalties to derive shelf allocations and assortments. Lal and Corstjens (1994) have an interesting perspective on the longer-term problem of creating store loyalty. They propose using the same decision to help generate store loyalty through promotion (via shelf space) of the store's own brands. It might be interesting to model the stocking and shelf allocation decisions as a dynamic process with other retailers competing (cooperating) in the same market.

\section{NOTES}

1. The question of whether consumer reactions to temporary "out-of-stocks" is the same as the reaction to permanent changes in assortment is also relevant to the illegal practice of "bait-and-switch" (purposely stocking out of some items in order to get consumers to buy other items which presumably have higher profit margins). Work by Moinzadeh and Ingene (1993) is relevant to this issue.

2. For a more complete description of the SA process see Borin et al. (1994).

3. For a standard normal distribution, 99 percent of the values will lie between -2.58 and +2.58 standard deviates. Therefore, if the desired interval is -.30 and +.30 each value drawn from the standard normal must be multiplied by $.30 / 2.58$.

4. Alphas were still constrained to be between zero and one.

5. The analysis performed in this section was done on the first set of true parameters. The results in this were initially reported in Borin, et al.

\section{REFERENCES}

Anderson, Evan E. (1979). "An Analysis of Retail Display Space: Theory and Methods," Journal of Business, 52(1): 103-118.

Borin, Norm (1992). An Analysis of Space and Assortment Tradeoffs in the Retail Environment. Unpublished PhD. Dissertation, The Darden Graduate School of Business Administration, University of Virginia.

Borin, Norm, Paul Farris and James Freeland (1994). "A Model for Determining Retail Product Category Assortment and Shelf Space Allocation," Decision Sciences, 25(3): 359-384.

Brown, William M. and W.T. Tucker (1961). "Vanishing Shelf Space," Atlantic Economic Review, 11(10): 9-13.

Bultez, Alain and Philippe Naert (1988). "SH.A.R.P.: Shelf Allocation for Retailers' Profit," Murketing Science, 7(Summer): 211-231. 
Bultez, Alain, Philippe Naert, Els Gijsbrechts and Piet Vanden Abelle (1989). "Asymmetric Cannibalism in Retail Assortments," Journal of Retailing, 65(2): 153-192.

Burgoyne, D.G. and C.B. Johnston (1968). "Are Shelf Space and Shelf Location Really Important," The Business Quarterly, 33(Summer): 56-60.

Cairns, James P. (1962). "Suppliers, Retailers, and Shelf Space," Journal of Marketing, (July): 34-36. Carpenter, Gregory S. and Donald R. Lehmann (1985). "A Model of Marketing Mix, Brand Switching and Competition," Journal of Marketing Research, (August): 318-329.

Corstjens, Marcel and Peter Doyle (1981). "A Model for Optimizing Retail Space Allocations," Journal of Marketing, 27(July): 822-833.

- (1983). "A Dynamic Model for Strategically Allocating Retail Space," Journal of the Operational Research Society, 34(10): 943-951.

Cox, Keith K. (1964). "The Responsiveness of Food Sales to Shelf Space Changes in Supermarkets," Journal of Marketing Research, (May): 63-67. . (1970). "The Effect of Shelf Space Upon Sales of Branded Products," Journal of Marketing Research, 7(February): 55-58.

Curhan, Ronald C. (1972). "The Relationship between Shelf Space and Unit Sales in Supermarkets," Journal of Marketing Research, 9(November): 406-412.

(1973). "Shelf Space Allocation and Profit Maximization in Mass Retailing," Journal of Marketing, 37(July): 54-60.

Ehrenberg, A.S.C. (1965). "An Appraisal of Markov Brand-Switching Models," Journal of Marketing Research, (November): 347-362.

Emmelhainz, Margaret A., James R. Stock and Larry W. Emmelhainz (1991). "Consumer Responses to Retail Stock-outs," Journal of Retailing, 67(Summer): 138-147.

Farris, Paul W., James Olver and Cornelius De Kluyver (1989). "The Relationship Between Distribution and Market Share," Marketing Science, 8(2): 107-128.

Frank, Ronald E. and William F. Massy (1970). "Shelf Position and Space Effects on Sales," Journal of Marketing Research, 7(February): 59-66.

Hansen, Pierre and Hans Heinsbroek (1979). "Product Selection and Space Allocation in Supermarkets," European Journal of Operational Research, 3: 474-484.

Hogg, Robert V. and Allen T. Craig (1978). Introduction to Mathematical Statistics. New York: Macmillan.

Ireland, John J. (1993). Estimating Direct Product Profit from Inexpensive Data. Working paper, Universitat Pompeu Fahra.

Kotzan, Jeffrey A. and Robert V. Evanson (1969). "Responsiveness of Drug Store Sales to Shelf Space Allocations," Journal of Marketing Research, 6(November): 465-469.

Krueckeberg H.F. and P.C. Davis (1966). "Consumer Response to Space Allocation in the Supermatket Dairy Department," Bulletin \#374, Agricultural Experiment Station, University of Delaware, Newark.

Lal, Rajiv and Marcel Corstjens (1994). "Shelf Space Allocation for Store Brands." Working paper.

Lee, Wayne (1961). "Space Management in Retail Stores and Implications to Agriculture." Pp. 523-537 in Marketing Keys to Profits in the 1960's, edited by W.K. Dolva. Chicago: American Marketing Association.

Marketing News (1982). "Pilot Study Finds Final Product Choice Usually Made in Store," 6 August:5.

Moinzadeh, Kamaran and Charles Ingene (1993). "An Inventory Model of Immediate and Delayed Delivery," Management Science, 39: 536-548.

Motes, William H. and Stephen B. Castleberry (1985). "A Longitudinal Field Test of Stockout Effects on Multi-Brand Inventories," Journal of the Academy of Marketing Science, 13(Fall): 54-68.

Nielsen Marketing Research (1992). Category Management. Positioning your Organization to Win. Chicago: NTC Business Books. 
Pauli, Hans and R.W. Huecker (1952). "Better Utilization of Selling Space in Food Stores," U.S. Department of Agriculture, Marketing Research Report No. 30, November.

Peckham, James O. (1963). "The Consumer Speaks," Journal of Marketing, (October): 21-26.

Reibstein, D.J. and H. Gatignon (1984). "Optimal Product Line Pricing: The Influence of Elasticities and Cross-elasticities," Journal of Marketing Research, 21: 259-267.

Shugan, Steven M. (1989). "Product Assortment in a Triopoly," Management Science, 15(March): 304-320.

Urban, Glen L. (1969). “A Mathematical Modeling Approach to Product Line Decisions,” Journal of Marketing Research, 6(February): 40-47.

Walter, C.K. and John R. Grabner (1975). "Stockout Cost Models: Empirical Tests in a Retail Situation," Journal of Marketing, 39(July): 56-68.

Walter, C.K. and Bernard J. La Londe (1975). "Development and Tests of Two Stockout Cost Models," International Journal of Physical Distribution, 5(3): 121-132.

Zufryden, Fred S. (1986). “A Dynamic Programming Approach for Product Selection and Supermarket Shelf-Space Allocation,” Journal Operational Research Society, 37(4): 413-422. 